\title{
A Concise History of World Population
}

\author{
by Massimo Livi-Bacci \\ 5th edition. Malden MA: Wiley-Blackwell 2012 \\ ISBN 978-0470673201 \\ Paperback, \$48.95, 286 pp.
}

\author{
Reviewed by Roderic Beaujot \\ Department of Sociology, University of Western Ontario \\ rbeaujot@uwo.ca
}

This little book is indeed concise, covering such a vast territory, but it is not at all superficial. It is a "mustread" for all serious students of population, by the renowned historical demographer and Past President of the International Union for the Scientific Study of Population, Massimo Livi-Bacci. Seasoned scholars who have pondered the big issues facing humanity will also want to take advantage of the author's vast knowledge, and check their own conclusions against Professor Livi-Bacci's careful summaries and discussions. The book has the advantage of the broad canvas that comes from the study of history-writ-large, but it also contains much valuable detailed information on the past and present.

Livi-Bacci is at his best on the big current issues of the discipline-for instance, on population and development, on Malthus versus Boserup, and on increasing or decreasing returns to scale. This is a remarkable and sensitive summary of these vast and important literatures. While Livi-Bacci frequently says that he is providing "simplifications of much more complex theories," this reviewer is impressed by the careful treatment of the various sides of the issues, the amount of data and information brought to bear, and the author's willingness to do justice to conflicting points of view as well as offer his own conclusions.

In terms of population and GDP, the following observation is noteworthy: The growth in per-capita GDP was virtually identical in United States and France between 1870 and 2000, at an average of 1.9 per cent per year. However, the differential population growths of these two countries changed the total GDP from a ratio of 1.4 to 1 in favour of the United States in 1870 to a ratio of 6.5 to 1 in 2000 (see p. 152). For the 28 largest less-developed countries, the period 1950-2000 can be generalized as an inverse relation between population growth and growth of GDP per capita (p. 197). That is, the countries with higher population growth had on average lower growth of per-capita GDP.

The following two conclusions are particularly significant: While economies of scale have found much empirical support in the past 150 years, "beyond certain limits, demographic growth creates diseconomies of scale, reversing a trend which seems to have dominated much of human history." The limits are not those of food production, as Malthus had thought—nor of non-renewable resources, where prices have declined or remained stable, contradicting the assumption of scarcity—but the quality of "spaces" where we can live and the renewable resources of water and air quality. This reviewer agrees that the major concerns are environmental, not as natural resources but as sinks for the deposit of the products of human activity, especially manifested as climate warming.

While technological improvements can solve many problems, and are ultimately unpredictable, the sheer scale is daunting. For instance, the Ehrlich equation is used to illustrate that the environmental impact in a stationary population like Italy could remain constant, even with a per-capita income increasing at a rate of 1.7 per cent per year for 2010-50, as long as technology reduces by 50 per cent the input of primary resources in each unit of production. However, for India the injections of technology would have to reduce to one-tenth the current impact per unit of production, to accommodate the expected 38 per cent growth in population and 
maintain the 5-per-cent annual increase in per-capita income that was experienced in the 2000-10 decade (see pp. 244-245).

Much use is made of the concepts of "choice" and "constraint," which are not unlike those of "structure" and "agency" that have been useful to sociology. But this is structure and agency writ very large, with the constraints being those of the environment, and the biological forces of mortality and disease. The concept of "choice" relates to union formation, fertility and migration, which of course are not always voluntary, either at the individual, family, or collective level. The concept of "choice" is also used at a very macro level: "More and more one hears that the control of population growth has been accepted as a positive value and so does not require demonstration or confirmation" (p. 256). This is agency at the level of humanity, in terms of making choices that will ensure survival of the species. The author concludes with the analogy of a vehicle speeding along a dangerous road toward an uncertain future: through human ingenuity we can improve the road and the vehicle, but ultimately the best is to have "a responsible driver able to see the signs of danger."

Besides these "big-picture" issues, there is also much in this book to interest those who like to follow important details on the world scene. For instance, French Canadians born before 1660 are used as an example of the highest total fertility rate (11.4 births per woman) for a select population group, demonstrating a fertility model of "very early unions with minimum birth intervals"-also operating in an environment of considerable resources, with mortality reduced through low population density and the selectivity of migration. The case of Ireland is noteworthy as an example of successive "demographic regimes." The introduction of the potato, allowing smaller plots of land, along with other factors, enabled young people to marry sooner, increased the population from 2.2 million in 1687 to 8.2 million in 1841. Then the Great Famine of 1847-48 would permanently upset the previous demographic order, bringing instead late marriage, considerable celibacy, 1.1 to 1.5 more deaths than normal, and an emigration exodus of 200,000 per year over 1847-1854. The population declined from 8.2 million in 1841 to 4.5 million in 1901 (pp. 62-65).

The role of international migration in world history is especially mapped with the European outward movements that accompanied colonialism, and the population pressure of the early phases of Europe's demographic transition. This movement of people was occurring at a time when the indigenous populations of North America and Australia/New Zealand were unable to withstand invasions. The globalizing trends of the post-World War II era were similar to those of the half-century preceding World War I, except that this time the population pressure of the early phases of the demographic transition has been from Asia, Latin America, and now Africa. Livi-Bacci observes that the globalization patterns following World War II have involved more movement of capital and goods than of people.

On the sustainability of extended survival, Livi-Bacci reminds us of the power of disease, which can baffle medical advances, the dependence of continued advances on political and economic sustainability, and the issues of higher disability and health needs in an aging population.

The reviewer is far from having done justice to the sophistication of this book, especially in showing the variety of human demographic experience, along with associated constraints and choices. Particularly noteworthy is the author's sensitivity to alternative interpretations, along with his "down-to-earth" theorizing that is always empirically based. 